Referencia para citar este artículo: Hernández-Rosete, D. \& Maya, O. (2016). Discriminación lingüística y contracultura escolar indígena en la Ciudad de México. Revista Latinoamericana de Ciencias Sociales, Niñez y Juventud, 14 (2), pp. 1161-1176.

\title{
Discriminación lingüística y contracultura escolar indígena en la Ciudad de México*
}

\author{
DANIEL HERNÁNDEZ-ROSETE** \\ Investigador Departamento de Investigaciones Educativas del Cinvestav, México. \\ OLIVIA MAYA *** \\ Profesora Universidad Nacional Autónoma de México, México.
}

\section{Artículo recibido en agosto 6 de 2015; artículo aceptado en octubre 20 de 2015 (Eds.)}

- Resumen (analítico): La discriminación lingüistica escolar es una forma de racismo cuya resistencia está poco documentada. En este artículo analizamos las creencias que favorecen la discriminación escolar de indígenas migrantes bilingües y describimos algunas de las respuestas que además existen como mecanismos de contracultura escolar. Realizamos una investigación fenomenológica de tipo constructivista social, cuyo trabajo de campo se realizó en dos escuelas del barrio de La Merced ubicado en la Ciudad de México. Encontramos que la pobreza, la condición migrante y el trabajo infantil persisten como estigmas en la vida escolar. Sin embargo la dificultad para hablar español es quizá la causa de violencia escolar más severa porque se naturaliza a través de apodos y burlas, pero paradójicamente genera un modelo de bilingüismo contracultural que fortalece las identidades lingüisticas de forma lúdica.

Palabras clave: Discriminación, contracultura, educación básica, indígenas, México, migración pendular (Thesauro de Ciencias Sociales de la Unesco).

\section{Language discrimination and indigenous school counterculture in Mexico City}

- Abstract (analytical): The school linguistic discrimination is a form of racism whose countercultural resistance is poorly documented. In this paper we analyze the beliefs that favor indigenous bilingual school discrimination migrants and describe some of the answers as there are also mechanisms of school counterculture. We conducted a phenomenological research constructivist social, whose field work was conducted in two schools in the neighborhood of La Merced is located in Mexico City. We found that poverty, migrant status and child labor persist as stigma in school life. However, trouble speaking Spanish is probably the cause of more severe school violence because it is naturalized through nicknames and teasing, but paradoxically generates a model of bilingualism counter strengthens linguistic identities in a playful way.

Key words: Discrimination, counter culture, basic education, indgenous, Mexico, commuting (Unesco Social Sciences Thesaurus).

\footnotetext{
Este artículo de investigación científica y tecnológica es producto de investigación cualitativa ("La migración indígena y la educación intercultural en el barrio de La Merced. Retos y alcances en la prevención de deserción escolar") dirigida por el autor principal con financiamiento del Consejo Nacional de Ciencia y Tecnología del gobierno mexicano (folio No. 85318). La investigación fue desarrollada y concluida entre el 22 de agosto de 2008 y el 7 de octubre de 2011. Área: Sociología; subárea: antropología.

** Investigador titular 3B en el Departamento de Investigaciones Educativas del Cinvestav. Antropólogo Social graduado en el Centro de Investigaciones y Estudios Superiores en Antropología Social, Doctor en Sociología de la Universidad Nacional Autónoma de México. Correo electrónico:drosete@cinvestav.mx

*** $\quad$ Profesora de asignatura en la Universidad Nacional Autónoma de México. Egresada de la Maestría en Antropología Social de la Escuela Nacional de Antropología e Historia, México. Correo electrónico: olismayag@hotmail.com
} 


\title{
Discriminação linguística e contracultura escola indígena na Cidade do México
}

\begin{abstract}
- Resumo (analítico): A discriminação linguística escola é uma forma de racismo, cuja resistência contracultural é pouco documentada. Neste artigo analisamos as crenças que favorecem os migrantes discriminação escola bilíngüe indígenas e descrevem algumas das respostas como existem também mecanismos contracultura escola. Foi realizada uma pesquisa fenomenológica construtivismo social, cujo trabalho de campo foi realizado em duas escolas no bairro de La Merced está localizado na Cidade do México. Descobrimos que a pobreza, condição de migrante e do trabalho infantil persiste como estigma na vida escolar. No entanto, dificuldade para falar espanhol é provavelmente a causa da violência escolar mais grave porque é naturalizada através de apelidos e provocações, mas, paradoxalmente, gera um modelo de balcão bilinguismo fortalece identidades linguísticas de uma forma lúdica.
\end{abstract}

Palavras-chave: Discriminação, contracultura, educação básica, índios, México, migração pendular (Thesaurus de Ciências Sociais da Unesco).

-1. Introducción. -2. Marco teórico. -3. Método y técnicas de investigación. -4. Universo de estudio y trabajo de campo. -Resultados. -5. El trabajo infantil como currículum oculto. De la desventaja educativa al prestigio comunitario. -6. El trabajo infantil y el olor de las aulas. -7. El bilingüismo como recurso de resistencia. -8. Migración pendular y rezago escolar. El indígena como precursor del atraso en el aula. -9. Conclusiones. -Lista de referencias.

\section{Introducción}

Al terminar la Revolución el Estado mexicano pretendió unificar la identidad nacional de una población caracterizada por la diversidad etnolingüística. La forma para lograrlo era la asimilación a través del lenguaje, que pronto se convirtió en un ideal nacionalista promovido por José Vasconcelos, quien veía en el mestizaje poblacional el recurso modernizador para acceder a un orden demográfico más homogéneo en términos lingüísticos. La noción de mestizaje en Vasconcelos está influenciada por ideas eugenésicas (Urías, 2007), basadas en los modelos de pensamiento naturalista y biomédico que pretendieron erradicar lo que llamaban rastro atávico atribuido a las poblaciones indígenas (Stern, 2005). Con la Secretaría de Educación Pública (SEP) a su cargo y a manera de cruzada nacional, Vasconcelos convirtió la enseñanza de la lectoescritura del español en el recurso más eficiente de asimilación cultural de población indígena no hablante del español en México.

La idea de rezago escolar en México mantiene su origen en ese saber de corte eugenésico (Granja, 2009) y parece recuperar vigencia, especialmente con la aparición de migrantes indígenas bilingües de origen rural y campesino en escuelas de la Ciudad de México. Es decir, persisten creencias que conciben a la diversidad etnolingüística como causa del rezago escolar pues entre otras condiciones las evaluaciones educativas siguen siendo estandarizadas y predominantemente en español. El problema más complejo es que las lenguas indígenas aún son concebidas por algunos profesores como expresiones dialectales y son vistas como inferiores lingüística y culturalmente frente al español (Hammel, 2001). En este artículo partimos de que en algunas escuelas urbanas del Distrito Federal existen formas de discriminación lingüística que se alimentan de los discursos eugenésicos sobre rezago escolar.

México está entre los países latinoamericanos con mayor diversidad lingüística (Aikman, 1999), sin embargo la inclusión educativa de población étnica aún enfrenta múltiples dificultades. La Secretaría de Educación Pública (SEP) se ha mostrado sensible ante esta situación y ha promovido políticas educativas con enfoques interculturales (Velasco, 2010), por ejemplo la consolidación de planes y programas de formación docente con enfoques interculturales y bilingües entre los que destaca la creación de bachilleratos y universidades con enfoques interculturales 
(Secretaría de Educación Pública del Distrito Federal, 2012), además de la conformación de un marco legal que a nivel de Constitución Política reconoce a México como un país pluriétnico y multilingüístico.

Sin embargo éstas políticas públicas no siempre han logrado incorporarse en las aulas como educación incluyente. Por ejemplo, algunos en estudios en México (Díaz-Couder, 1991) y en otros países de América Latina (Hecht, 2010, Lavado, 2005, Neufeld \& Thiested, 1999, Sinisi, 2010) sugieren que la educación multicultural bilingüe facilita la transición a la educación monolingüe en español, es decir, la prioridad termina siendo la evaluación de lectoescritura en español. Esta dinámica ha sido documentada en México como una condicionante de deserción escolar temprana atribuible a causas de discriminación lingüística (Galeana, 1997). Se trata de un problema poco estudiado ya que se ha priorizado el análisis de la deserción escolar ligada a la precariedad económica y al trabajo infantil (Rebolledo, 2007).

Aunque aún es escasa la investigación etnográfica que analiza la relación entre discriminación lingüística y las desventajas educativas en población indígena bilingüe, en este artículo nos interesa describir los recursos de resistencia a la discriminación lingüística que los estudiantes indígenas despliegan para contender con esta forma de violencia escolar. Además analizamos algunas explicaciones que los docentes dan al ausentismo y al rezago escolar de población indígena migrante.

\section{Marco teórico}

En México la discriminación lingüística ha sido documentada como una práctica de poblaciones "mestizas" y monolingües que acosan a indígenas no hispanohablantes (Friedlander, 1977, Ossola, 2013), sin embargo también existe entre personas que comparten el mismo origen lingüístico e incluso regional y sobre todo cuando hay indicios de bilingüismo (Lastra, 1992). Para analizar este fenómeno en el contexto escolar consideramos necesario asumir que la discriminación lingüística entre indígenas expresa relaciones de poder y dominación jerárquicamente conformadas (Wade, 1997), asimétricas e históricamente institucionalizadas, que son naturalizadas $y$ legitimadas a través de contextos como la vida familiar y la vida escolar.

Otro aspecto que tomamos en cuenta es que la discriminación lingüística no sólo es un fenómeno opresivo, estructural y estructurante de los sujetos, en este artículo le concebimos como una forma de violencia que puede generar mecanismos de resistencia que no siempre se inscriben en la lógica de lo abiertamente contestatario, es decir, no siempre implica una confrontación absoluta con el carácter opresivo de la lengua hegemónica como lo sugiere Coronado (1995). Por eso nos hemos apegado al enfoque de Scott (2000), que sugiere la existencia de formas de resistencia discretas que, si bien son cotidianas, corresponden al territorio de lo furtivo pues se trata de prácticas sociales con las que se consigue evitar los cercos de vigilancia o el severo control de los procesos disciplinarios sin que necesariamente se asuma una postura de confrontación política. Este fenómeno se observa en contextos escolares, en donde las normas disciplinarias basadas en lectoescritura del español parecen reforzar las formas de resistencia lingüística que documentamos en este trabajo.

Consideramos, entonces, que la resistencia lingüística es un sistema de comunicación que permite la sobrevivencia de una lengua subordinada (Coronado, 1995) en contextos diglósicos, pero no siempre es una consecuencia de procesos políticos e ideológicos abiertamente asumidos. Creemos que hablar de resistencia lingüística supone también procesos de flexibilización en torno a las prácticas del bilingüismo (Hecht, 2011), particularmente porque le consideramos como un acto lúdico y subversivo que se constituye en una potente forma de resistir el desplazamiento lingüístico que generalmente ocurre en contextos diglósicos como la escuela.

Con este encuadre, articulamos una hipótesis de trabajo considerando que las determinantes estructurales de la discriminación lingüística escolar pueden estar acompañadas de respuestas individuales, que no siempre son tomadas en cuenta como parte de los modelos 
que analizan este fenómeno. En ese sentido el estudio requirió de un referente epistémico que, además de ofrecer un abordaje estructural, nos permitiera reconocer que los individuos poseen márgenes de respuesta y reflexividad situada frente a las estructuras de poder (Giddens, 2003). Como por ejemplo, las dinámicas de resistencia que despliegan los niños y niñas indígenas a través de su propio bilingüismo frente a la discriminación. De modo que si bien éste es un hecho social opresivo, existen formas de resistencia observables tanto en aulas como en recreos y las describimos como parte de los hallazgos de este estudio.

\section{Método y técnicas de investigación.}

Nuestra investigación se inscribe en la corriente fenomenológica del constructivismo socialy estábasada enentrevistas en profundidad, con las que se exploran los significados atribuidos a lo real (Berger \& Luckmann, 1999). Uno de los dilemas para construir nuestro universo de informantes tuvo que ver con la definición antropológica de identidad étnica. Consideramos necesario retomar de Cardoso de Oliveira (2007) que el proceso de representación de la etnicidad está ligado a las ideologías dominantes, de ahí la importancia ética al definir lo étnico como un fenómeno que no se limita a lo folclórico ni al lenguaje y que incluye dinámicas de identificación que, entre otros aspectos, suponen la autoadscripción. Sin la intención de agotar este campo de estudio tomamos en cuenta corrientes interpretativas sobre pertenencia étnica tanto en términos de autoadscripción como de adscripción atribuida (Barth, 1976). En el primer caso consideramos con Weber (2000) que un aspecto sociológico trascendente tiene que ver con el sentimiento de pertenencia a una comunidad étnica. Este planteamiento considera que lo étnico es un proceso de adscripción comunitaria pero además un acto de autoadscripción subjetiva, es decir la etnicidad es una forma de elección social inherente al individuo.

En el segundo caso se trata de categorías étnicas asignadas desde lo teórico a ciertos grupos sociales. En este caso, la adscripción, es útil porque permite diferenciar lo indígena de las culturas campesinas (Montemayor, 2008, Warman, 2003), pero lo más importante fue reconocer que el lenguaje no puede ser tenido como el único marcador de identificación étnica (Del Val, 1999, Wade, 1997, Camus, 2002). También resultó valioso tomar en cuenta los posicionamientos de Bartolomé (2004) quien asume que lo indígena se liga al conocimiento de los ciclos agrícolas, pero sobre todo al comunitarismo expresado a través de los sistemas de mayordomías y especialmente a la estructura calendárica de las fiestas religiosas en sus lugares de origen, independientemente de que reconocieran o no hablar algún idioma distinto al español. Con este enfoque queremos rescatar la idea de que las formas de hacer y organizar el mundo de vida en comunidad expresan un capital intangible propiamente indígena que no se limita sólo a la lengua.

\section{Universo de estudio y trabajo de campo}

El universo de estudio (Tabla 1) está constituido por 46 informantes y se dividió en tres grupos: 1) niños y niñas indígenas bilingües en proceso escolar, 2) madres de familia bilingües, 3) docentes, psicólogas y autoridades escolares. Nos acercamos a los menores y sus familias bajo el criterio de que fueran migrantes de primera generación y con antecedentes de bilingüismo. Dimos prioridad a las narraciones de niños y niñas indígenas en sus roles de estudiantes y como miembros de grupos familiares, sus historias revelan que provienen de cuatro estados: Chiapas, Estado de México, Michoacán y Oaxaca, además son hablantes bilingües de tseltal, mazahua, náhuatl, mixteco y zapoteco.

Los profesores entrevistados son 3 varones y 2 mujeres mayores de cincuenta años con fuertes anclajes de identificación con la cultura indígena y campesina, todos son migrantes de primera generación, bilingües y originarios de la Mixteca Alta. Este perfil es particularmente importante para comprender las dinámicas interétnicas que se dan en las aulas observadas, pues algunas de las prácticas de hostigamiento son propiciadas por los propios docentes.

Contamos con el apoyo de las psicólogas de la Unidad de Servicio y Apoyo a la Educación 
Regular (Usaer), quienes conocían las historias migratorias y condiciones de existencia de algunos de los estudiantes que entrevistamos. Fueron de gran ayuda porque aportaron el vínculo de confianza con las familias elegidas, además también forman parte del universo de informantes pues aunque no son población indígena aportaron información clave para comprender las dinámicas de discriminación y resistencia en las aulas.

Tabla 1. Universo de estudio.

Grupo 1. Niños y niñas indígenas en proceso escolar

Grupo 2. Madres de familia

Grupo 3. Autoridades educativas

$$
\mathrm{N}=46
$$

El trabajo de campo abarcó los ciclos escolares de 2010 y 2011 en dos planteles, uno adscrito a la Coordinación General de Educación Intercultural Bilingüe (Cgeib) y el otro a la Subdirección de Educación Básica (SEB), ambos de la Secretaría de Educación Pública (SEP). Están ubicados en la zona del mercado de la Merced $^{1}$, una de las regiones receptoras de población indígena migrante en la Ciudad de México. Se eligió este barrio porque buena parte de sus escuelas públicas atienden población indígena, que vive en condiciones de pobreza y exclusión (Monnet, 1995), es el caso de los hijos de indígenas migrantes que no hablan español o que están en proceso de aprenderlo.

1 La Merced está en la delegación Venustiano Carranza. Los datos censales revelan que el 31 por ciento de sus viviendas presentan algún nivel de hacinamiento y el 33 por ciento de su población ocupada percibe un ingreso máximo de hasta dos salarios mínimos (Consejo Nacional de Población, 2011). Por otro lado, los índices de desarrollo humano indican que la tasa de mortalidad infantil es del 20 por ciento y, no obstante que el 97 por ciento de su población es alfabeta, cerca del 30 por ciento de las personas entre 6 y 24 años no asiste a la escuela (Consejo Nacional de Población, 2011). Destaca que el 10 por ciento de la población de 15 años o más no ha concluido su primaria (Consejo Nacional de Población, 2011). Se trata de una demarcación con niveles notables de desarrollo urbano que, sin embargo, mantiene rostros de exclusión y marginalidad que pueden estar muy ligados a la pobreza como forma de vida entre población indígena.
Las instalaciones de los dos planteles fueron diseñadas para ser escuelas, pero forman parte de conjuntos urbanos no aptos para el proceso educativo. Especialmente el que está adscrito a la Cgeib, pues colinda con un campo de tiro de la Secretaria de Seguridad Pública del Distrito Federal (SSPDF). En este plantel se oyen ráfagas de armas de fuego, lo que crea un ambiente estridente y violento al que parecen haberse habituado las poblaciones que ahí trabajan y estudian. El otro plantel, está en una de las calles con actividades comerciales más importantes de la zona, de modo que, desde sus aulas se oyen los cánticos de vendedores ambulantes.

Otro aspecto que merece atención es que los planteles están ubicados en uno de los contextos más terribles de violencia sexual de la Ciudad de México. La prostitución femenina en la Merced existe como parte de una imagen urbana violenta, pues se exhibe en forma de carrusel. Es una forma de pasarela o marcha colectiva de prostitutas que caminan en fila y formando una elipse con su andar. Los callejones de Manzanares y Santo Tomás se distinguen por las multitudes de hombres que, a cualquier hora del día, rodean los carruseles. Es notable el silencio tumultuario, que se interrumpe con los sonidos del caminar colectivo de las mujeres y niñas indígenas que son explotadas sexualmente. Estos dos callejones aparecen regularmente en los relatos de las niñas entrevistadas, quienes se ven en necesidad de transitar muy cerca de los carruseles cuando van o regresan de la escuela.

\section{Resultados}

\section{El trabajo infantil como currículum oculto. De la desventaja educativa al prestigio comunitario}

Para las familias estudiadas, el trabajo infantil, tanto el doméstico como el extradoméstico, es determinante de la subsistencia alimentaria. Estas jornadas agudizan las desventajas escolares de los niños y las niñas porque trabajar y estudiar llega a convertirse en una forma de vida. Son menores que asisten exhaustos a la escuela, por eso es frecuente verles dormir en clase. 
Paradójicamente, es el ámbito escolar uno de los contextos en donde encuentran una tranquilidad contrastable con sus ritmos laborales:

"Trabajamos todos los dias, también trabajamos el sábado y el domingo porque es cuando más venta hay, pero esos días no voy a la escuela. Entonces descansamos un poquito por eso, porque no voy a la escuela los sábados ni los días domingo" (Niña mazahua, 12 años, cuarto de primaria).

Hay familias indígenas con jornadas de trabajo de doce horas diarias, de lunes a domingo, iniciando a las cinco de la mañana con un desayuno a base de café y tortilla tostada con sal. Desde ese momento los menores portan el uniforme escolar y en grupo familiar se trasladan a la Central de Abasto, ahí recogen verduras en los vertederos. Es una recolección selectiva de papas y zanahorias, que procesan después a pie de banqueta en la Merced. Este trabajo es considerado sucio, porque pepenan entre restos de basura, sin embargo pone en evidencia los aspectos más obvios del desperdicio que genera una sociedad orientada al consumo. Los desechos se convierten, a través del trabajo de estas familias, en productos consumibles. La labor radica en desbrozar a cuchillo las verduras, retirando las partes descompuestas, de tal forma que se obtiene una pieza limpia y fresca. Finalmente es cortada en pequeños trozos cuadriculados con los que se rellenan bolsas de plástico de aproximadamente trescientos gramos. Este trabajo es una forma de reciclaje sumamente complejo que está basado en conocimientos agrícolas sobre recolección y clasificación alimentaria.

En la Merced, "poner el puesto" implica organizar y gestionar un espacio que no va más allá de dos metros cuadrados. No sólo es un lugar para la mercantilización, sino que puede favorecer procesos de vida familiar y de vida escolar ya que es un contexto público y privado donde igual se preparan alimentos para consumo familiar, que se atiende al marchante o se hacen tareas escolares. Es un espacio en donde el idioma materno se convierte en un recurso estratégico para interactuar con la población mestiza, sirve, por ejemplo, para instruir sobre los costos de la mercancía. Es paradójico porque la intimidad que produce el lenguaje materno existe en medio del bullicio que hay en esta zona.

El puesto genera rangos y jerarquías familiares que expresan formas de solidaridad grupal, pero también reflejan estructuras de poder y prestigio que se capitalizan entre las niñas indígenas, pues se les nombra "marchantas" cuando pueden negociar precios con los clientes pero sobre todo cuando se les ve con capacidad para resolver dilemas derivados de la interacción con policías y líderes locales, quienes generalmente solicitan pagos por derecho de venta en vía pública.

Ser indígena, mujer y migrante en la Merced favorece la desigualdad educativa y no sólo porque la escuela sea reproductora de roles de género, sino porque la vida familiar también lo es pues agudiza las desigualdades entre miembros de un mismo grupo doméstico. Por ejemplo, las responsabilidades ligadas a la división sexual del trabajo coexisten con labores escolares que en términos cotidianos constituyen una doble o hasta triple jornada para las niñas. Es decir, las responsabilidades de crianza y de preparación de alimentos son delegadas en las niñas, quienes se ven en necesidad de alimentar a hermanos incluso de mayor edad:

"En el puesto hago de comer y compro tortilla para mis hermanos. La que se encarga del puesto soy, pero ellos siempre me ayudan cuando estamos solos" (Niña mazahua, 12 años, quinto grado).

Existen, sin embargo, experiencias formativas relacionadas con la responsabilidad que implica atender un puesto a pie de banqueta que generan ventajas, más allá de las habilidades matemáticas que distinguen a las niñas inmersas en trabajo infantil, tal como lo sugieren otros estudios (Carraher, Carraher \& Schliemann, 2007). Para una menor, llevar el puesto significa asumir responsabilidades propias de un adulto, especialmente porque implica un proceso de resolución de dilemas y de rendición de cuentas. Ser una buena "marchante" significa ganar prestigio frente a la mirada de otros menores, pero sobre todo ante los parientes que tutelan el proceso de aprendizaje implícito en 
el acto de llevar el puesto. De esta forma son presentadas ante el mundo social indígena, pues se vuelve una noticia que llega a los lugares de origen a través de los circuitos de comunicación migratorios. Lo que permite a la menor ser reconocida más allá del ámbito escolar: primero en el contexto del mercado de la Merced $^{2}$ y luego en su comunidad de origen, en donde el prestigio se produce y adquiere cuando la niña es vista como responsable de un puesto.

Este proceso da cuenta de la feminización de los mercados de trabajo informales en la zona de la Merced, muy ligado por cierto a los patrones de fecundidad pues las edades en que éstas niñas pueden llegar a ser madres fluctúan entre los 12 y los 14 años. Rangos muy similares a los parámetros de fecundidad en zonas rurales. Observamos por ejemplo, que los padres de familia tienen expectativas de escolaridad muy bajas para sus hijas. Esto agudiza y reproduce las desventajas educativas de las niñas, pues mientras de los varones se espera que concluyan la secundaria de las hijas se considera satisfactorio que a lo más concluyan los tres o cuatro primeros ciclos escolares que corresponden a educación primaria:

"Mi papá apoya a mis hermanos, quiere que terminen la secundaria. Pero luego me dice que ir a la escuela es como tirar dinero a la basura porque dice que luego me van a venir a pedir y que pronto me voy a junta con alguien. Dice que cuando ya sea marchanta nada más seré de tener hijos. Pero no soy así de ser mamá nada más, por decir que yo quiero ir a la escuela, me gustaría ser abogada para poder defender a la gente de tanta injusticia que se mira. Por eso mi abuelita que está en el pueblo dice que si quiero seguir estudiando pues dice que me regrese al pueblo, que porque allá sí puedo terminar hasta la secundaria" (Niña mazahua, 11 años, tercer grado).

2 Los locatarios del mercado de la Merced también intervienen en la producción de distinción social, sus representaciones son de tipo moral y favorecen diferencias entre lo que ellos consideran el buen indígena según etnia y lugar de origen. Se trata de ideas estereotipadas sobre las niñas mazahuas, a quienes se les considera hábiles en el proceso de comercialización de verduras en vía pública, mientras que a las otomíes se les considera desorganizadas y descuidadas con los hijos.
El trabajo infantil femenino agudiza las desigualdades de educación formal, pues está muy emparentado con los estereotipos de género que rigen la nupcialidad y que propician deserción escolar femenina. Es decir, acreditarse como marchanta frente al mundo masculino puede leerse también como una mujer "disponible" para la maternidad, precisamente en una edad que coincide con los rangos deserción escolar femenina en las dos escuelas analizadas.

\section{El trabajo infantil y el olor de las aulas}

Culturalmente el olor existe como un recurso de distinción social y refuerza la razón clasificatoria del mundo: "lo bello no huele" dice Laporte (1989, p. 86). La discriminación en escuelas de la Merced no se reduce a la condición etnolingüística, también obedece a imaginarios sociales sobre el mal olor en las aulas. Algunos profesores creen que este fenómeno tiene que ver con la presencia de indígenas en los salones. El mal olor origina entonces, clasificaciones simbólicas que muestran la formación higienista del docente, quien encuentra en la falta de limpieza un marcador de identificación étnica:

"En las escuelas se ven muchas diferencias sociales, los salones son muy importantes en ese sentido porque nos dejan ver que los niños, los indígenas son sucios, no son de baño diario, uno los identifica por ese olor" (Profesor mixteco, Cuarto grado).

La clasificación olfativa del aula expresa nociones morales sobre el cuerpo sucio en escuelas presumiblemente limpias. Es una forma de violencia que origina estigmas, pero es socialmente aceptada y hasta funcional en contextos de epidemias, cuando el contacto físico propaga formas de parasitosis como los piojos. En ese sentido, el olor se construye socialmente porque adquiere el estatus simbólico para atribuir al indígena migrante el rol de víctima propiciatoria. Prácticamente todos los profesores en los planteles que estudié creen que la población indígena propaga los piojos. Algunos me recomendaron tener cuidado con los indígenas que entrevistaría, 
ya que estaba por empezar la primavera y con ella, según ellos, irremediablemente llegaría la temporada escolar de piojos:

"Los indigenas traen las epidemias de piojos cuando regresan de sus pueblos, allá estuvieron conviviendo con animalitos de campo. Se ve que es cuando regresan en enero o en febrero porque es cuando empiezan los piojos acá" (Profesor mixteco, Cuarto grado).

Días después un brote estaba declarado a nivel del Distrito Federal y tras dos semanas más, la infestación prácticamente afectaba a todo el sistema escolar en el Distrito Federal, lo que incluye escuelas privadas y públicas de educación básica. La propagación generalizada de pediculosis en la ciudad sugiere que no necesariamente está causada por la falta de higiene, ni tiene su origen en población indígena ni en migrantes. Al parecer hay un ciclo reproductivo de los piojos que se engancha con algunas condiciones sociales, pero lo que llamó nuestra atención fue la respuesta de la comunidad escolar para dar una explicación definitiva sobre el origen de la epidemia. Se crea un chivo expiatorio y, a la vez, surgen explicaciones que legitiman el rol epidemiológico del paciente cero, o sea aquel que origina una epidemia. Es la condición que la sociedad occidental históricamente ha dado a los grupos sociales temidos por su diferencia lingüística y cultural. Este caso recuerda la epidemia de peste de 1344 en Europa, que fue vista como resultado de la natural maldad de los gitanos, cuya condición étnica ligada al nomadismo y a un lenguaje tenido como exótico eran evidencias suficientes para concebirles como víctimas propiciatorias del desastre (Delumeau, 1989).

Podemos asegurar que la discriminación en las escuelas observadas no sólo tiene que ver con hablar un idioma distinto al español, sino además porque su origen indígena es asociado a la falta de higiene y no a la pobreza material en que viven. En esto consiste la relación entre raza y herencia, es decir, el cuerpo sucio y desprolijo parece naturalizarse y explicarse como un hecho inherente a la etnicidad.

Otro aspecto muy ligado a esta representación sobre lo sucio es que en ambas escuelas la apariencia física es meticulosamente vigilada, por lo que asistir con el uniforme limpio es quizá el mandato moral más fuerte que enfrentan los indígenas que trabajan y estudian. Aunque nunca vimos que se negara el acceso a los estudiantes que no lo portaban, el uniforme es un dispositivo disciplinario que se inscribe en lo que Foucault (2002) denomina encauzamiento normativo. Sin embargo exigirlo puede violentar los derechos educativos, particularmente de aquellos que no pueden ceñirse al requisito de presentarse a clase con el uniforme limpio y completo ${ }^{3}$. Los casos que pudimos observar no sólo llevaban uniformes sucios, sino incompletos pues suelen presentarse sólo con algunas de las prendas oficiales. Es común ver estudiantes vistiendo, en pleno invierno, sólo con pantalón o falda y playera escolar, sin cierres, ni botones. Considerando que el uniforme no es obligatorio, asistir así a clase parece un despropósito, pero también es cierto que el uniforme es un recurso de identificación y forma parte de lo que significa ser estudiante. Definitivamente portarlo, aunque sea incompleto, es una forma de sentirse alumno y saberse parte del mundo escolar.

\section{El bilingüismo como recurso de resistencia}

Algunas investigaciones (Hecht, 2011, Novaro, Bortón, Diez \& Hecht, 2008, Romer, 2005, Sinisi, 1999), sugieren que el bilingüismo en aulas urbanas genera prácticas de discriminación que favorecen la diglosia ${ }^{4}$. En el caso de la Ciudad de México, se ha

3 En el artículo 38 de los lineamientos de escuelas públicas de educación básica en el Distrito Federal (Secretaría de Educación Pública del Distrito Federal, 2012) se indica que el uniforme no es obligatorio y su falta no puede ser objeto de sanción, ni causal para impedir el acceso al plantel.

4 Entendemos como diglosia el contexto en donde una comunidad de habla utiliza dos lenguas distintas, una de las cuales es considerada más importante que las demás. (Ferguson, 1959). Por otro lado, Fishman (1967) sugiere que una sociedad es diglósica en tanto las lenguas utilizadas sean funcionales para la comunidad de habla, sin embargo ésta idea aplica también para el concepto de bilingüismo. La discusión acerca de sí algunos grupos étnicos en México son bilingües o díglotas no está acabada, pero es evidente que asumir que en las aulas el español sería la lengua de prestigio es caer en un reduccionismo, pues el uso de las lenguas indígenas en las comunidades de origen de los migrantes podría considerarse también de ésta forma. Por eso, en este trabajo se decidió utilizar el concepto de bilingüismo pues no pretendemos plantear una discusión en términos sociolingüísticos sino un análisis antropológico. 
documentado el miedo de indígenas migrantes al rechazo social por hablar idiomas distintos al español (Galeana, 1997, Rebolledo, 2007, Del Val, 1999, Díaz-Polanco, 1997). En esta investigación encontramos además un proceso de clasificación que la escuela produce en relación con la idea de rezago, pues desde los primeros días de trabajo de campo observamos que cuando los estudiantes ingresan a primer grado sin saber hablar español eran considerados con problemas de audición o incluso cognitivos:

E: ¿por qué te gustaría aprender a hablar mixteco?

I: Para ayudar también a mí hermana a hablar español. Porque ella no sabe mucho español y por eso está en el salón de los niños que hablan a señas.

E: ¿Por qué está con esos niños?

I: es que no habla bien español y por eso le estamos enseñando, para que sea de hablar bien el español (Niño mixe, 9 años, tercer grado).

Cuando conocimos este relato buscamos la opinión de una de las psicólogas de la Unidad de Servicio y Apoyo a la Educación Regular (Usaer) que trabaja en la escuela, quien nos explicó que entre los profesores persiste la creencia de que cuando no hablan español se trata de "... niños con problemas de lenguaje". En el peor de los casos, son tenidos como personas con dificultades de aprendizaje y suelen ser clasificados como menores con retraso mental:

"Llegan a la ciudad chiquitos de 6 años, a veces no hablan español. Me los mandan a sesiones de terapia de lenguaje $y$ entonces apenas inician cursos y ya los clasifican como niños con problemas de lenguaje. Desde ese momento ya son maltratados porque son niños a los que los profesores consideran con retraso mental" (Psicóloga responsable de Usaer).

Consideramos que "retraso mental" es un término psiquiátrico, por cierto en desuso, con el que se patologiza la condición lingüística pues da origen a un estigma de tal magnitud que algunos de los estudiantes con sobre edad escolar y que no hablaban español fueron enlistados en grupos de educación especial para personas con discapacidad auditiva severa. Por eso es factible verles interactuar en los recreos con niños sordomudos o con discapacidades motrices, a quienes conocieron durante su primer año escolar. Después de dos o tres años son alumnos bilingües que además de hablar perfectamente el español aprenden lenguajes de señas que usan los sordomudos.

El hecho de pasar a segundo o tercer grado de primaria y no hablar español puede ser tenido como un "sintomático" atraso cognitivo con respecto a la población que sí lo habla. Persiste entonces un monolingüismo hegemónico que es definitivo y definitorio para medir el nivel de atraso escolar. Son representaciones con cargas de violencia eugenésica pues suponen que el bagaje etnolingüístico expresa formas de rezago sociocultural, en tanto se cree que posee atributos de inferioridad de origen biológico y orgánico (Stern, 2005). Una de sus implicaciones es que dan lugar a formas de segregación escolar que no son tan evidentes para quien observa el aula multiétnica.

Aunque la discriminación lingüística puede ser severa, los hallazgos del presente estudio revelan que existen prácticas de respuesta lingüística a las burlas y otras formas naturalizadas de esta violencia escolar. Es una práctica de resistencia que acompaña al niño bilingüe en su trayecto por la vida escolar y constituye lo que consideramos resistencia contracultural al racismo lingüístico.

Los niños y niñas indígenas bilingües que llegan a la ciudad enfrentan el tabú familiar de hablar en público el idioma materno y aprenden, desde el contexto familiar, a decir que sólo hablan español. Esto tiene fundamento en el escarnio que representa el hablar en otro idioma en presencia de otros que dicen sólo hablar español:

E: ¿tus compañeros saben que tu mamá habla zapoteco?

I: No.

E: ¿O qué tu hermanita habla o entiende el zapoteco?

I: Ella sí entiende pero yo no. Un poquito aprende.

E: Al principio no me querías decir que tu mamá habla Zapoteco. ¿Por qué no me querías decir? 
I: Como estaban muchos niños, por eso me daba mucha pena decirlo adelante de todos los niños.

E: Te daba pena, ¿por qué?

I: No sé. Siempre cuando digo algo me da pena.

E: ¿Los niños se llegan a burlar?

I: Unos sí y unos no.

E: ¿Por qué unos sí y otros no?

I: Porque unos se ríen y otros no, pero los que no se ríen es porque no les gusta burlarse de otros, pero son pocos los niños así de respeto.

(Niña zapoteca, 10 años, tercer grado).

De los treinta y dos niños y niñas indígenas que entrevistamos, sólo tres reconocieron hablar un idioma distinto al español. Pero durante los recreos, en los salones y en sus puestos comerciales a pie de banqueta pudimos escucharlos hablar en otros idiomas. En ese sentido se advierten cambios generacionales en torno a los significados del ser indígena bilingüe en un mismo grupo doméstico. Los menores viven con un bilingüismo que rompe el tabú del lenguaje materno, por tanto no necesariamente tienen prácticas lingüísticas propias de la diglosia pues aunque no se asumen como hablantes de otra lengua distinta al español, utilizan públicamente el idioma materno como un recurso para interactuar entre pares frente al marchante o frente al compañero de pupitre que se dice mestizo y monolingüe. Pero en particular lo hacen en contextos escolares, cuando se aplican exámenes y la lógica disciplinaria dicta guardar silencio. En ese momento hablar en mixteco o tojolabal se vuelve estratégico. De hecho es una práctica de aulas multilingüísticas bastante común que sirve para construir espacios de intimidad lingüística en un contexto público en el que se prohíbe conversar:

"Se pasan las respuestas del examen, se les oye hablar en su dialecto y se ríen todo el tiempo de sus compañeros porque no les entienden" (Psicóloga responsable de Usaer, DSTV).

No queda del todo claro que estas conversaciones tengan la intención de divulgar las respuestas. Pero el acto adquiere el sentido de un desafío a la autoridad, sobre todo al uso de la llamada lengua de prestigio, en este caso el español.

Los niños y niñas indígenas bilingües aprenden a usar la lengua materna para producir un cerco simbólico y crear intimidad y hasta privacidad en espacios públicos:

E: ¿Tu mamá les enseña a hablar tsotsil?

I: No, ella no quiere que hablemos en tsotsil.

E: ¿Te ha llegado a preguntar si quieres aprender a hablar tsotsil?

I: No, pero sí lo hablamos. Nomás cuando jugamos con mis hermanos y allá en mi pueblo o a veces en el puesto, aunque nos regañe mi mamá por hablar así en tsotsil.

(Niña tsotsil, 9 años, tercer grado).

Este fenómeno se ve con mucha más contundencia en los recreos y en actividades deportivas, contextos en los que el patio escolar se vuelve de facto un espacio multilingüístico. Para la institución escolar se trata de un tiempo asignado a lo "recreativo", quizá por eso no siempre tiene la validación de un espacio de aprendizajes. Durante los recreos advertimos que para los menores este momento es mucho más que un tiempo fuera académico dispuesto para jugar, ya que ocurren interacciones de discriminación y resistencia sumamente complejas. Los idiomas se usan con un sentido lúdico para organizar los juegos colectivos que requieren alianzas o para decidir qué se compra y con quién. Hay actividades diferenciadas por sexo-género pero con arraigos lingüísticos similares, pues mientras las niñas emplean su tiempo y recursos monetarios en el consumo de alimentos, los niños apuestan dinero en juegos como la Rayuela. En ambos casos se trata de decisiones mediadas por diálogos que figuran como consejería en idiomas distintos al español.

El uso de idiomas indígenas también resulta en la transgresión del orden disciplinario en el aula. Por ejemplo, enseñar groserías en otro idioma bien puede pasar por una forma casi picaresca y lúdica de interacción entre niños que hablan diversos idiomas, incluyendo el español. Sin embargo, para algunos docentes esta práctica es entendida como una agresión, aunque no siempre sea esa la intención del niño bilingüe: 
E: ¿aquí en la escuela hablas tzeltal?

I: Sí con mi hermano.

E: ¿Y con algunos otros compañeros o amigos?

I: No. Pues luego todos quieren aprender groserías, pero no les quiero enseñar porque pues son groserías. Es que una vez así les dije y luego uno le dijo a una muchacha, es que le dio una cachetada y el chavo le dijo una grosería de mi dialecto y la maestra entonces dijo: ¿qué significa eso? Y le dijo el chamaquito y luego a mí ¿quién te enseñó eso? El Santiago -le dijo, y luego me fue a acusar y me castigó la maestra.

E: ¿Te castigó la maestra?

I: Me llevó a la directora. Por eso luego ya no les quiero enseñar groserías y todo eso. (Niño tzeltal, 8 años, segundo grado).

\section{Migración pendular y rezago escolar. El indígena como precursor del atraso en el aula}

El multilingüismo en el aula no es bien visto por los docentes en ninguna de las dos escuelas analizadas. Entre ellos persiste la idea de que este origina rezago escolar, pues los estudiantes que no hablan español requieren de atención especializada para que adquieran la lengua hablada antes de su alfabetización. Esto representa un problema si el docente no recibe el apoyo necesario para acompañar a aquellos alumnos hablantes de otras lenguas:

"Hay compañeros que creen que los migrantes o son sordos o no pueden aprender correctamente a leer porque los ven como niños con retraso mental, pero no, el problema es que uno como docente no está bien preparado para recibir niños que no hablan español, entonces a veces lo más fácil es mandarlos a educación especial" (Profesor de tercer grado, Náhuatl).

Surge entonces la idea de rezago ante la urgencia de priorizar y consolidar la lectoescritura en español:

Rev.latinoam.cienc.soc.niñez juv 14 (2): 1161-1176, 2016 http://revistalatinoamericanaumanizales.cinde.org.co DOI: $10.11600 / 1692715 x .14219060815$
"La mayoría ha ido a la escuela y cursan varios grados, pero cuando llegan aquí no hablan español. Yo no puedo enseñarles a hablar en español, en primer y segundo grado nuestra tarea es la enseñanza de la lectura y la escritura, las funciones básicas en matemáticas, no enseñar a hablar español. Eso niños requieren atención especializada pero no tenemos ese apoyo, por eso se vuelven un problema de rezago para el grupo" (Profesora de segundo grado).

Aunado a este dilema también está el ausentismo de estudiantes indígenas, muy relacionado con la estructura de fiestas patronales en las localidades de origen. Detectamos que algunos miembros de las familias ocupan cargos de representación en los sistemas de mayordomías locales, lo que favorece ciclos de retorno anual a los pueblos de origen e implica ausencias escolares durante dos semanas. También dejan de asistir a clases por una semana en el contexto del día de muertos (1 de noviembre), cuando el trabajo infantil en la Merced se incrementa notablemente, pues se trata de un contexto de vendimia particularmente importante para el grupo familiar. La ausencia escolar por migración más importante se observa en las fiestas de fin de año, pues los salones se ven vacíos desde principios de diciembre y hasta fines de enero, cuando regresan de sus comunidades. Es decir el rezago escolar de los estudiantes indígenas está condicionado tanto por las condiciones de pobreza y de trabajo infantil como por las necesidades de adquisición de la lengua hablada.

Además observamos otra variable. La discriminación etnolingüística que ejercen los profesores ha sido poco estudiada como precursora de desventajas educativas. Entre profesores pueden existir creencias sobre rezago escolar asociadas a la dificultad de algunos indígenas migrantes para hablar correctamente el español. Especialmente porque la alfabetización persiste como un modelo hegemónico de lectoescritura en español, incluso en el plantel con perfiles de educación intercultural. Es una forma de discriminación 
lingüística pues supone la existencia de un español puro que los estudiantes alfabetizables deben hablar y pronunciar correctamente. Este uso del lenguaje fue referido por los menores indígenas como "la forma de habla normal del español", ya sea por su entonación, por las conjugaciones de los tiempos verbales o por el uso correcto de artículos y de conjunciones:

E: ¿Y usted profesora cómo puede identificar a los niños indígenas?

I: Pues no los identifico hasta que los escucho hablar porque si no hablan, no me doy cuenta. Casi la mayoría habla diferente a nosotros. En el Distrito Federal dicen que hablamos cantadito y ellos no hablan así. Entonces depende de cómo se expresen porque luego dicen endenantes o palabras incompletas.

E: ¿Cómo cuáles?

I: Pues como antis o endenantis o algo así ¿no? O sea, se escuchan raros, se les sale la palabra y los corrijo. No se dice naiden, no se dice pos, -les digo-es pues. Entonces ya se van corrigiendo. Pero eso los limita mucho porque los otros niños indígenas que sí hablan bien se burlan de ellos (Maestra de sexto grado).

Las variantes lingüísticas del español y sus diversas entonaciones favorecen la aparición de apodos, que son vistos por los profesores como travesuras entre pares y no como mecanismos de violencia. Entre los menores los apodos son repetidos sin conocer su origen y los asumen como parte de una práctica social dada, no la cuestionan. Los profesores de mayor edad asignan los sobrenombres, pues para ellos es legible el sentido peyorativo de nombrar al niño migrante como El Madaleno, La María o El Piporro. Estos apodos se repiten en los planteles estudiados y representan figuras que la televisión mexicana produjo en los años setenta para satirizar al indígena monolingüe, analfabeto y campesino recién llegado a la Ciudad de México (Friedlander, 1977). Pero sobre todo producen estereotipos del migrante impedido para hablar "correctamente" el español.

Hablar incorrectamente el español puede ser visto como un síntoma de rezago educativo, se vuelve un estigma cuando se cree que dificulta la alfabetización y que el alumno, al ser sometido a una evaluación estandarizada, puede bajar el promedio global del grupo evaluado. Por ejemplo, cuando los profesores están inscritos en el plan de carrera magisterial son evaluados anualmente por la Secretaría de Educación Pública para conocer el nivel de su desempeño a través de pruebas que se aplican a los grupos a los que imparten clases. Cuando realizamos esta investigación estas evaluaciones estaban vigentes y se denominaban pruebas de Evaluación Nacional de Logros Académicos en Centros Escolares (Enlace), eran aplicadas a las escuelas públicas de nivel básico en las materias de español y matemáticas. Si el grupo evaluado muestra algún nivel de rezago educativo, los intereses monetarios del docente son afectados ya que puede perder el acceso a becas compensatorias que complementan sus sueldos.

La prueba Enlace favorece lo que llamamos ausentismo escolar inducido, es decir el docente expulsa temporalmente del aula a los migrantes no alfabetizados o que no hablan bien el español, es una práctica generalizada entre los propios profesores el día en que se aplica esta prueba. Es una forma de segregar a los menores considerados con rezago educativo, que en los casos de los planteles analizados siempre resultaron ser poblaciones indígenas bilingües.

Otra forma de rezagar al alumno, particularmente al migrante se da en el momento en que llegan a la escuela buscando insertar en la vida escolar a sus hijos. Cuando llegan a la ciudad es frecuente que el ciclo escolar haya iniciado o esté por concluir, lo que representa un serio problema de desfase escolar pues surge un dilema de evaluación escolar para las autoridades que reciben a esta población. Las familias migrantes se enfrentan entonces, a un sistema escolar que al estandarizar la evaluación grupal, busca colocar a los estudiantes migrantes en un grado académico tomando en consideración su edad y el hecho de saber o no leer y escribir en español, pero no toman en cuenta sus conocimientos ni antecedentes curriculares. Por ejemplo, conocimos casos que presentaron la boleta del ciclo escolar anterior, pero las autoridades del 
plantel invalidaron aquellos estudios dado que eran niños que no hablaban, ni leían el español. Esto obliga a repetir el ciclo académico anterior, lo que en términos de historial genera sobre edad escolar y termina por reforzar la idea de rezago educativo como una condición étnica y de migrante campesino. Encontramos dos casos de menores que habían estudiado hasta segundo de primaria en escuelas rurales, en donde las clases se impartían en mixteco. Estos alumnos llegaron a la Ciudad de México alfabetizados en mixteco y con hábitos estudiantiles, es decir, estaban acostumbrados a asistir todos los días a la escuela, a hacer tareas, a organizar su semana $\mathrm{y}$ mes en atención al acto de ir a la escuela. El problema tiene que ver con el hecho de que no hablan español, pues vienen de zonas rurales monolingües y que por ser rurales se asumen como rezagadas.

\section{Conclusiones}

La vida escolar observada sugiere que los estudiantes identifican en los usos del idioma español formas para distinguirse entre sí como personas campesinas o urbanas. Por eso, aprender a vivir en la ciudad entre otras cosas incluye adquirir sentimientos de rechazo a las formas de vida campesinas, que son tenidas como indicios de vida indígena. Sin embargo, lo urbano, lo indígena y lo campesino no siempre son excluyentes, pues se producen interacciones que pueden incluso dar lugar a un modo de vida contracultural. Por ejemplo, aunque la discriminación etnolingüística impide a los estudiantes indígenas asumir su propio bilingüismo como bagaje de prestigio, los menores indígenas entrevistados encuentran en el lenguaje materno un recurso para responder a burlas y apodos.

Aunque describimos algunos rostros de la resistencia lingüística al racismo escolar, también hemos documentado cuatro casos de discriminación. El primero tiene que ver con la representación del mal olor en el aula, como si se tratara de una condición natural de la población indígena. Lo que omite el peso del trabajo infantil: es el caso de menores indígenas que estudian y trabajan. El segundo está relacionado con el brote de una epidemia de pediculosis durante el ciclo escolar 2008-2009 y que ha sido atribuida a poblaciones indígenas. El tercero está referido a las creencias y prácticas instituidas por la escuela que generan segregación y que son observables en los recreos, los exámenes y el control de acceso al plantel cuando el uniforme está sucio o incompleto. Pero sobre todo, y esto vale la pena subrayarlo, durante la aplicación de pruebas Enlace. Este es el contexto más evidente de exclusión, pues genera lo que denominamos ausentismo escolar inducido. El cuarto caso es el de los menores que no logran dominar la lectoescritura en español antes de segundo de primaria y que por esa razón son considerados como estudiantes con problemas de aprendizaje, por lo que se les clasifica como personas con discapacidad intelectual. Esta clasificación puede estar ligada al sentido de vergüenza que es aprendido por vía oral entre menores indígenas, quienes verbalizaron este proceso como un hecho común que, sin embargo, pueden pasar por alto en los recreos y en algunos otros contextos de negociación que se caracterizan por la diversidad etnolingüística, pero sobre todo que se distinguen por su dimensión lúdica como los recreos y durante los exámenes. Aunque ninguno reconoció hablar otro idioma diferente al español, la mayoría habla otras lenguas y las utiliza como medios para crear cercos de confidencialidad en la escuela. Son niños y niñas bilingües que reconocen la importancia del español en su vida como comerciantes y estudiantes.

Las prácticas escolares de segregación tienen relación con la formación de los docentes sobre lo que debe ser un alumno en proceso de alfabetización en español. Algunos de los profesores atribuyen el rezago a la condición indígena y no a la dinámica que engloba el círculo pobreza/migración pendular. Tampoco parecen advertir el impacto social del trabajo infantil como precursor de desventaja educativa en el aula multilingüística. Por eso, consideramos que la formación docente es un antecedente importante para comprender cómo se produce la discriminación del niño migrante bilingüe en aulas urbanas que pasan a segundo o tercer grado sin hablar correctamente español. 
De las cuatro formas de discriminación creemos importante destacar que la relacionada con el tema del mal olor reviste una trascendencia especial pues en la explicación que algunos docentes dan de este fenómeno se advierte la vigencia del pensamiento higiénico-pedagógico emparentado con el racismo científico que caracterizó los discursos de la educación en el México postrevolucionario. Remite a la representación positivista, evolutiva y unilineal que confronta barbarie con civilización y que ha servido para naturalizar las condiciones de pobreza en que viven las poblaciones indígenas en la ciudad. Esta lógica alimentó los proyectos médicos sobre higiene escolar ${ }^{5}$ desde fines del siglo XIX hasta bien iniciado el XX y mantienen una notable vigencia en las aulas observadas en el marco de este estudio. Junto con la representación del mal olor, aparece la pediculosis, que sigue siendo atribuida a las poblaciones indígenas que son vistas como las responsables de esos brotes epidémicos.

Hay un avance importante en las políticas de educación intercultural, pero las aulas aún muestran deficiencias en materia discriminación etnolingüística. El fenómeno aparentemente sólo involucra a alumnos, sin embargo los docentes intervienen en su legitimación. Además persisten prácticas y discursos escolares que al no poder atender la diversidad etnolingüística de las aulas, atribuyen condiciones de discapacidad cognitiva al indígena monolingüe. Este fenómeno es de hecho una forma de discriminación etnolingüística escolar $\mathrm{y}$ está arraigada en las creencias médicas que veían regularidades en la relación entre raza y herencia. Pero antropológicamente ya es insostenible la determinación entre raza y herencia, ese vínculo lo creó la eugenesia para sustentar idea de atavismo indígena.

La resistencia lingüística que documentamos no necesariamente es experimentada como un instrumento de lucha política. Es decir, las poblaciones observadas asumen su bilingüismo sin pretensiones de empoderamiento contestatario e interactúan de

5 Por ejemplo, Josefina Granja (2009) menciona que en 1908 se organiza el Servicio Higiénico Escolar, que tenía la finalidad de inspeccionar escuelas del Distrito Federal para rastrear y erradicar a "niños con retraso mental". manera lúdica. Así, reivindican el derecho a la diferencia lingüística desde una praxis social ligada a la agencia de niños y niñas indígenas que ciudadanizan su derecho a la educación, sobre todo porque algunos de ellos asumen su otredad lingüística en la vida escolar.

La posibilidad de establecer condiciones de reconocimiento intercultural no sólo depende de las políticas de Estado, sino de la sensibilización de profesores y autoridades de mando medio (Directores de Plantel e Inspectores), en tanto actores inmersos en la interacción de la vida cotidiana escolar. Lo que está en juego es el derecho a la educación intercultural como principio para convivir en aulas sin violencia.

\section{Lista de referencias}

Aikman, S. (1999). De la asimilación al pluralismo cultural: autodeterminación indígena sobre educación en la amazonia peruana. EnP.Gonzalbo(coord.)Educación rural e indígena en Iberoamérica, (pp.265286). México, D. F.: El Colegio de México.

Barth, F. (1976), Los grupos étnicos y sus fronteras. La organización social de las diferencias culturales. México, D. F.: Fondo de Cultura Económica.

Bartolomé, M. (2004). Gente de costumbre y gente de razón. Las identidades étnicas de México. México, D. F.: Siglo XXI.

Berger, P. \& Luckmann T. (1999). La construcción social de la realidad. Buenos Aires: Amorrortu.

Camus, M. (2002). Ser indígena en Ciudad de Guatemala. Ciudad de Guatemala: Flacso.

Cardoso de Oliveira, R. (2007). Identidad étnica, identificación y manipulación. Etnicidad y estructura social. México, D. F.: Ciesas, Uami.

Carraher, T., Carraher, D. \& Schliemann A. (2007). En la vida diez, en la escuela cero. México, D. F.: Siglo XXI.

Consejo Nacional de la Población (2011). Índice de marginación por entidad federativa y municipio 2010. México, D. F.: Fondo Población de las Naciones Unidas.

Coronado, G. (1995). La resistencia lingüística como instrumento de lucha política. Anales de Antropología, 32, pp. 179-189. 
Del Val, J. (1999). La población indígena y el desarrollo. Sobre la construcción de una sociedad pluriétnica y multicultural. México, D. F.: Demos.

Delumeau, J. (1989). El miedo en Occidente. Madrid: Taurus.

Díaz-Couder, E. (1991). Lengua y sociedad en el medio indígena de México. En A. Warman \& A. Argueta (eds.) Nuevos enfoques para el estudio de las etnias indígenas en México, (pp.143-192). México, D. F.: Porrúa, Ciih.

Díaz-Polanco, H. (1997). Cambios en la consideración de la población indígena y su autonomía. México, D. F.: Demos.

Ferguson, Ch. A. (1959). 'Diglossia'. Word, 15, pp. 325-340.

Fishman, J. A. (1967). Bilingualism with and without diglossia: diglossia with and without bilingualism. Journal of Social Issues, 23. pp 29-38.

Friedlander, J. (1977). Ser indio en Hueyapan. Un estudio de identidad obligada en el México contemporáneo. México, D. F.: Fondo de Cultura Económica.

Foucault, M. (2002). Vigilar y castigar. Nacimiento de la prisión. Buenos Aires: Siglo XXI.

Galeana, R. (1997) La infancia desertora. México, D. F.: Fundación SNTE para la Cultura del Maestro Mexicano.

Giddens, A. (2003). La constitución de la sociedad. Bases para la teoría de la estructuración. Buenos Aires: Amorrortu.

Granja, J. (2009). Contar y clasificar a la infancia. Las categorías de la escolarización en las escuelas primarias de la Ciudad de México 1870-1930. Revista Mexicana de Investigación Educativa, 14, pp. 217-254.

Hammel, E. (2001). Politicas del lenguaje $y$ educación indígena en México. Orientaciones culturales y estrategias pedagógicas en una época de globalización. En R. Bein \& J. Born (eds.) Políticas lingüísticas. Norma e identidad, (pp. 143-170). Buenos Aires: Universidad de Buenos Aires.

Hecht, A. (2010). Categorías étnicas. Un estudio con niños y niñas de un barrio indígena. Revista Latinoamericana de
Ciencias Sociales, Niñez y Juventud, 8 (2), pp. 981-993.

Hecht, A. (2011). Encrucijadas entre las familias wichi y las escuelas: Procesos de apropiación, resistencia y negociación en la Educación Intercultural Bilingüe. Formosa: LAP.

Laporte, D. (1989). Historia de la mierda. Valencia: Pre-textos.

Lastra, Y. (1992). Sociolingüística para hispanoamericanos. Una introducción. México, D. F.: El Colegio de México.

Lavado, P. (2005). La dinámica de la deserción escolar en el Perú: un enfoque usando modelos de duración. Lima: Centro de Investigación de la Universidad del Pacífico.

Montemayor, C. (2008). Los pueblos indios de México. Evolución histórica de su concepto y realidad social. México, D. F.: Random House Mondadori.

Monnet, J. (1995). Usos e imágenes del Centro Histórico de la Ciudad de México. México, D. F.: DDF.

Neufeld, M. \& Thisted J. (1999). El crisol de razas hecho trizas: ciudadanía, exclusión y sufrimiento. En M. Neufeld \& J. Thisted (comps.) De eso no se habla. Los usos de la diversidad sociocultural en la escuela, (pp.23-56). Buenos Aires: Editorial Universitaria.

Novaro, G., Bortón, L., Diez, M. \& Hecht, A. (2008). Sonidos del silencio, voces silenciadas. Revista Mexicana de Investigación Educativa, 13,36, pp. 173201.

Ossola, M. (2013). Jóvenes indígenas en la frontera: relaciones entre etnicidad, escolaridad y territorialidad. Revista Latinoamericana de Ciencias Sociales, Niñez y Juventud, 11 (2), pp. 547-562. Doi: 10.11600/1692715x.1126180612.

Rebolledo, N. (2007). Escolarización interrumpida. Un caso de migración y bilingüismo indigenas en la ciudad de México. México, D. F.: Universidad Pedagógica Nacional.

Romer, M. (2005). Los hijos de inmigrantes indígenas en la Ciudad de México. Una propuesta de tipología de identidades 
étnicas. Actas Latinoamericanas de Varsovia, 28, pp. 53-66.

Scott, J. (2000). Los dominados y el arte de la resistencia. México, D. F.: ERA.

Secretaría de Educación Pública del Distrito Federal (2012). Lineamientos para la Organización y el Funcionamiento de los Servicios de Educación Inicial, Básica, Especial y para Adultos de Escuelas Públicas en el Distrito Federal. México, D. F.: Administración Federal de Servicios Educativos en el D. F.

Sinisi, L. (1999). La relación nosotros-otros en espacios escolares "multiculturales". Estigma, estereotipo y racialización. En M. Neufeld \& J. Thisted (comps.) De eso no se habla. Los usos de la diversidad sociocultural en la escuela. Buenos Aires: Editorial Universitaria de Buenos Aires.

Sinisi, L. (2010). Integración o inclusión escolar ¿un cambio de paradigma? Boletín de Antropología y Educación, 1, pp. 11-14.

Stern, A. (2005). Eugenic Nation. Faults and Frontiers of Better Breeding in Modern America. Oakland: University of California Press.

Urías, B. (2007). Historias secretas del racismo en México (1920-1950). México, D. F.: Tusquets.

Velasco, S. (2010). Políticas (y propuestas) de educación intercultural en contraste. En S. Velasco \& A. Jablonska (coords.) Construcción de políticas educativas interculturales en México: debates, tendencias, problemas, desafios, (pp. 63-113). México, D. F.: Universidad Pedagógica Nacional.

Wade, P. (1997). Gente negra, nación mestiza. Dinámicas de las identidades raciales en Colombia. Bogotá, D. F.: Siglo del Hombre Editores.

Warman, A. (2003). Los indios mexicanos en el umbral del milenio. México, D. F.: Fondo de Cultura Económica.

Weber, M. (2000). Comunidades étnicas. Economía y sociedad. México, D. F.: Fondo de Cultura Económica. 